\title{
Application of Kraljic and stowage techniques to define purchasing strategies to reduce cost overruns in a food service company
}

\author{
Guillermo Pretell ${ }^{1}$, Edgardo Carvallo, Msc ${ }^{1}$, Iliana Macassi, Msc ${ }^{1}$ and Christian del Carpio, Msc ${ }^{2}$ \\ ${ }^{1}$ Industrial Engineering, Universidad Peruana de Ciencias Aplicadas (UPC), Lima - Perú, u201214975@upc.edu.pe, \\ edgardo.carvallo@upc.pe,pcadlmac@upc.edu.pe \\ ${ }^{2}$ Direction of research, Universidad Peruana de Ciencias Aplicadas (UPC), Lima - Perú, pcelcdel@upc.edu.pe
}

\begin{abstract}
A prepared food supply company presents a cost overrun in the purchase of food of $20 \%$ with respect to the base price used in the fixing of the sale price of the rations, said cost overrun is due to bad planning since it is not counted with defined purchasing strategies and market conditions are not valued. After an analysis, cause - root, it is identified that the main cause of the cost overruns are unscheduled purchases, so the study area has been delimited to the acquisition and transport of products. The proposed solution to reduce cost overruns is based on the application of Kraljic in order to define the company's purchasing policies and strategies and the implementation of stowage techniques in food transportation and storage.

Following the application of the aforementioned solutions, it was possible to mitigate the unscheduled purchase situations, bringing with it a 92\% decrease in the cost overruns for the purchase of food products, and the ration cost overrun indicators were improved by $15 \%$ and purchases not programmed in $22 \%$.
\end{abstract}

Keywords - Kraljic, Supply chain, Purchasing management, Stowage techniques, Food industry

\section{INTRODUCTION}

In July 2019, INEI, National Institute of Statistics and Informatics, published in its monthly report that the catering sector contracted by $19 \%$ due to the high dependence on the sector of particular events, being these sporadic and short-lived, likewise a variation of prices of products of mass consumption of $2 \%$ to $2.5 \%$ is indicated, the item of supply of food by order at business level presents a stagnation in terms of customers and number of service providers, being mostly closed circle and of high complexity of requirements, with a high rate of losses and cost overruns in raw materials which vary from $30 \%$ to $40 \%$.

At the business level, the Peruvian State is one of the most attractive clients, with its health, military and prison institutions standing out, the latter being the one with the highest volume of consumers. The prepared food service provided to the INPE, National Penitentiary Institute of Peru, presents conditions for the mandatory provision of the service, the most prominent being: perennial supply of rations, comprehensive care to all inmates, programming of anticipated and non-modifiable rations, fixed and non-negotiable service price; Under these premises, for companies, it is vitally important to have a purchasing strategy that guarantees the continuous supply of

Digital Object Identifier (DOI):

http://dx.doi.org/10.18687/LACCEI2020.1.1.90

ISBN: 978-958-52071-4-1 ISSN: 2414-6390 food and is not affected by wholesale price variations throughout the year of the agreed service. In this context, the company under study has an approximate cost of S/ 1007000 originated by unscheduled purchases of which $75 \%$ derive from poor purchasing planning and $18 \%$ from a poor method of transporting food products.

In the supply chain of processed foods, it is vitally important to have a defined purchasing policy focused on guaranteeing the continuous flow of products, for this the study and analysis of suppliers responsible for supplying the required products is required, and in Secondly, to have an appropriate transport plan to avoid the damage and loss of products in the transfer of these. Described by the company's problems, Kraljic is presented as the ideal tool to generate the strategies and purchasing policies and the use of stowage techniques recommended by SENASA, National Service of Agri-food Health and Quality, body in charge of advising and regulate the transport of food at the national level, as a method of transport to eliminate situations that generate reprocessing of purchases, for this purpose a proposal is developed combining both methods in order to reduce cost overruns.

The research methodology covers 3 phases, the analysis and identification of the problem, development of purchasing policies using Kraljic and the implementation of stowage techniques in the area of food transport, which covers $83 \%$ of the cost overruns in the acquisition of products presented by the company

\section{STATE OF THE ART}

\section{Typology I: Supply Chain Management (SCM)}

The management of the supply chain (SCM), consists of carrying out coordinated activities associated with the flow of goods and information from the obtaining of the raw material to the delivery of the product to the final customer [1]. The SCM has been exploited as a competitive advantage of companies over their competitors, covering certain specific areas, in order to develop them and turn them into their competitive advantage [2].

The management of the food supply chain (FSCM) covers production, distribution and consumption activities and operations, managing food quality and safety problems efficiently and effectively [3]. Weak management of the FSCM 
can generate perishable foods (such as fruits and vegetables) lost by up to 492 million tons worldwide [4].

\section{Typology II: Kraljic portfolio model (KPM)}

This case study focuses on purchasing management and strategies as tools for reducing cost overruns in food procurement, Kraljic was the first to contextualize the portfolio approach for use in supply and purchasing management, since not all the products can be obtained in the same way, so it is necessary to use different purchasing strategies according to market conditions and aspect related to suppliers [5]. The Kraljic (KPM) portfolio model, according to Kraljic, a company's supply strategy depends on the impact on profits and the risk of supply [6].

The attributes of the impact on the profit factor are the percentage of goods and services purchased in relation to total costs, and supply risks are defined as the difficulty of maintaining continuous supply under the conditions initially required [7].

The KPM aims to reduce the risk of supply and increase the purchasing power of the buyer [8], presents four quadrants where the products are distributed after evaluating the criteria of supply risk and economic impact, assigning them the following labels for their subsequent treatment:

Lever elements have a high economic impact and low supply risk and include strategically important expenses in a large market with many alternative suppliers. The buyer's domain is high in terms of relative power, since the purchasing power is actively used to obtain better deals with interchangeable suppliers [9].

Strategic elements, high economic impact and high supply risk. The purchasing strategy to be applied is to develop close cooperation relationships with suppliers, making them strategic partners of the company. The distribution of power is equitable and the level of interdependence is very high [10].

Routine elements, low impact on profits and low risk of supply. The purchasing strategy is to improve the purchasing power through standardization and grouping of the purchase requirements, the power between the company and the suppliers is equitable since both have mutual dependence [11].

Bottleneck elements, low economic impact and high supply risk. The purchasing strategy for this category is to maintain the continuity of supply, through unique and long-term contracts, as well as to have possible alternatives [12].

As evaluation tools, authors such as Sanjaykumar establish an analysis of supplier supply risk in order to assess whether the proposals are viable, and then establish supplier monitoring and evaluation measures through performance indicators (KPI) [13]. KPIs are metrics used to measure and quantify the performance of strategies or processes, allowing to anticipate and correct unplanned problems and take corrective actions to minimize cost overruns.

\section{Typology III: Good food handling practices.}

Senasa establishes a guide to good food handling practices (GFHP) and feed[14], specifying the following criteria for: classification of products according to their nature, packaging methods, level of packaging quality, handling techniques, means and handling tools.

It also develops a guide to good loading practices (GLP) in order to establish criteria for loading, unloading and means of transporting food and feed [15] defining the criteria of: classification of freight transport units (FTU), loading and unloading tools, organization methods within a FTU.

\section{Typology IV: Stowage techniques}

Stowage techniques seek to reduce the movement of products within FTUs in transport to minimize product damage and loss, and optimize load stacking to employ the maximum viable load within FTUs [16]. The stowage defines the products used for stacking and the techniques to be used to guarantee the stability of said stacking, considering [17]:

- Type and resistance of pallets.

- Distribution of pallets in FTU according to their download.

- Grip and hold techniques.

- Mechanisms and fastening products.

- Classification of products by weight and dimension

\section{Typology V: Food and feed transport regulations}

In Peru, the institution in charge of regulating the transport and loading of food is Senasa who issues regulations and instructions for the regulation of the activities already mentioned. In the Carrier Guide publication [18], the general terms of qualification, distribution method and load assurance to be fulfilled by the FTU are provided Likewise, the Food Safety Guide establishes cleaning methods for handling and food preservation characteristics [19].

\section{PROPOSED MODEL}

The company under study is a prepared food supply company, which works with state institutions, INPE in this case, with an annual work period, the provision of the service includes certain conditions specific to the sector such as: price not modifiable or negotiable, programming rations 15 days in advance, ratio of non-modifiable rations, respect good eating habits (no use of frozen food); Under these premises, the rations already approved by the INPE must be met, taking full responsibility for the food supply.

In the last year, the company had an extra cost of $20 \%$ of the base price per budgeted ration, s/. 1007 035, these cost overruns originate in the following areas: purchases with $75 \%$, storage with $7 \%$ and transport with $18 \%$. The storage area has been 
discriminated because of its low percentage value. A root cause analysis was performed, which is shown in Fig. 1, to find the causes of the cost overruns, finding that the 4 root causes with the greatest impact are:

- Ration mix planning: $35 \%$

- Unscheduled purchases: $39 \%$

- Non-standardized stowage method: $4 \%$

- Cargo insurance not defined: $7 \%$

Four root causes were identified, of which the first two root causes of the area of identified purchases are within the study area of purchasing management, several authors define the model proposed by Kraljic as the best tool to define purchasing strategies and turn them into a competitive advantage, said model is defined as a $2 \times 2$ matrix that analyzes the strategic importance of the products purchased, Gelderman [20], he added an additional step by fragmenting the quadrants to identify the most suitable areas to change quadrants to the products in order to obtain a better bargaining power and thus obtain a better price from the suppliers.

The last 2 root causes belonging to the transport area are the causes of reprocesses of purchases of products damaged in the cargo, stowage, insurance and transport in the FTU. Stowage techniques were applied to take full advantage of the FTU and the classification of elements according to load, use and characteristics, all following the parameters established by SENASA.
The model to follow to reduce the cost of unscheduled purchases will cover the purchases and transportation areas to establish a purchase policy and a transport guide, this model is shown in Fig. 2.

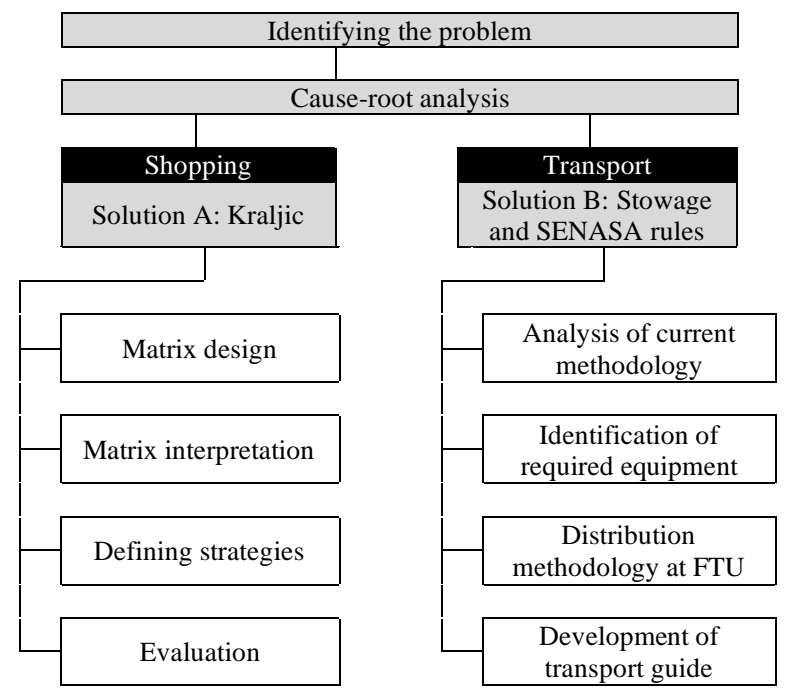

Fig. 2 Proposal model

The solution model is divided into 2 parts: the first is analysis, which ranges from identifying the problem, its respective root causes; the second part is the application of Kraljic's solution A, KPM, in which the necessary procedures are designed to build a robust and sustainable purchasing policy over time; and solution B, the application of food transport standards as a work regulation scheme and stowage techniques as a work method for loading, distribution and product assurance, these methods are applied in combination according to the phases indicated current regulations.

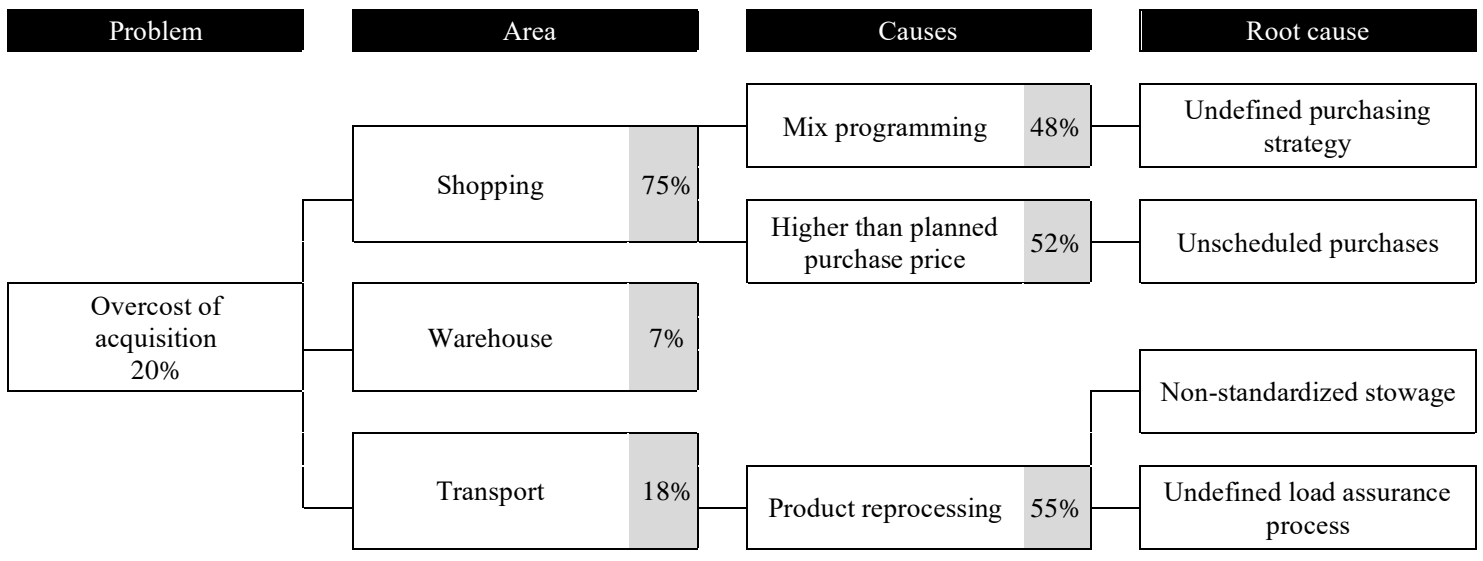

Fig. 1 Cause - root analysis 
The solution model is divided into 2 parts: the first is analysis, which ranges from identifying the problem, its respective root causes; the second part is the application of Kraljic's solution A, KPM, in which the necessary procedures are designed to build a robust and sustainable purchasing policy over time; and solution B, the application of food transport standards as a work regulation scheme and stowage techniques as a work method for loading, distribution and product assurance, these methods are applied in combination according to the phases indicated current regulations.

\subsection{Solution A: Kraljic}

As described in the previous paragraphs, the KPM, Fig. 3, is used to generate a purchasing policy, having a panoramic view of the products and greater bargaining power as an advantage when bidding with suppliers, for this Kraljic It analyzes products in two dimensions of supply risk ( $\mathrm{X}$ axis) and economic impact ( $\mathrm{Y}$ axis), which will evaluate internal qualification criteria on a Likert scale, which qualifies from lowest to highest impact with a score of 1 to 5 points giving a total of 35 points, for example, Kang [13], proposes categories within each quadrant after an analysis of the evaluation criteria of each axis allowing a better approach and Hesping, makes a statistical compilation of the criteria and weights it in percentage terms according to its use and incurrence in each quadrant [21].

For this study, the products purchased have been grouped according to their supply relationship by the suppliers, that is, if the suppliers generally offer all the products, the lentil, pallar, bean and similar products have been grouped into the family "F13: Beans", the application of this previous step has resulted in 5 product elements, which carry the prefix" $\mathrm{P}$ ", and 13 families, who carry the prefix" $F$ ".

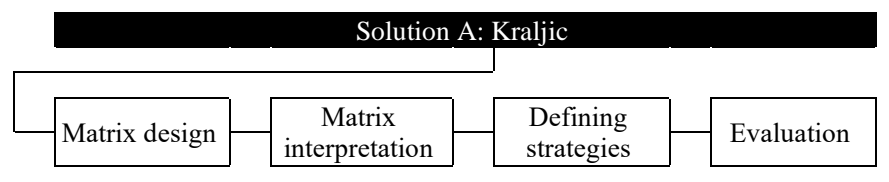

Fig. 3 KPM application scheme

The design of the KPM matrix is carried out by axis, for the $\mathrm{X}$-axis the market and product evaluation categories are selected in which evaluation criteria were selected adapting the Hesping analysis to the business turnover characteristics such as $\mathrm{C} 1$ : variation of market, $\mathrm{C} 2$ : flexibility of volume, $\mathrm{C} 3$ : shortage of suppliers, C4: competitive demand, C5: difficulty of substitution, C6: difficulty of transport and C7: difficulty of storage. For a better understanding of the application of the method, the values and events referring to the elements " $\mathrm{P} 1$ : Rice" and "P3: Chicken" will be described, in this case said elements P1 and P3 obtained a score of 17 and 24 points respectively in the $\mathrm{X}$ axis, as shown in Table $\mathrm{I}$.
TABLE I

RISK OF SUPPLY (AXIS X)

\begin{tabular}{|c|c|c|c|c|c|c|c|c|c|}
\hline \multirow{2}{*}{\multicolumn{2}{|c|}{ Internal criteria }} & \multicolumn{5}{|c|}{ Market } & \multicolumn{2}{|c|}{ Product } & \multirow{2}{*}{ Total } \\
\hline & & C1 & $\mathrm{C2}$ & C3 & C4 & C5 & C6 & C7 & \\
\hline \multicolumn{2}{|c|}{ Item - Score } & 1 to 5 & 1 to 5 & 1 to 5 & 1 to 5 & 1 to 5 & 1 to 5 & 1 to 5 & 35 \\
\hline $\mathrm{P} 1$ & Rice & 2 & 3 & 2 & 3 & 5 & 1 & 1 & 17 \\
\hline $\mathrm{P} 2$ & Oil & 1 & 1 & 2 & 1 & 3 & 1 & 1 & 10 \\
\hline P3 & Chicken & 3 & 3 & 1 & 5 & 4 & 4 & 4 & 24 \\
\hline $\mathrm{P} 4$ & Bread & 1 & 2 & 3 & 1 & 5 & 1 & 1 & 14 \\
\hline P5 & Sugar & 2 & 1 & 2 & 3 & 3 & 1 & 2 & 14 \\
\hline $\mathrm{F} 1$ & Carne & 3 & 3 & 1 & 5 & 5 & 4 & 4 & 25 \\
\hline $\mathrm{F} 2$ & Grocery & 2 & 1 & 1 & 1 & 3 & 1 & 1 & 10 \\
\hline F3 & Seasoning & 2 & 1 & 4 & 2 & 3 & 2 & 2 & 16 \\
\hline $\mathrm{F} 4$ & Cereal & 2 & 2 & 2 & 2 & 5 & 1 & 2 & 16 \\
\hline F5 & Noodle & 1 & 2 & 2 & 3 & 4 & 2 & 2 & 16 \\
\hline F6 & Vegetables & 3 & 1 & 3 & 3 & 2 & 4 & 4 & 20 \\
\hline F7 & Tubers & 4 & 2 & 1 & 5 & 3 & 1 & 1 & 17 \\
\hline $\mathrm{F} 8$ & Limón & 5 & 1 & 2 & 3 & 2 & 2 & 2 & 17 \\
\hline F9 & Queso & 2 & 1 & 3 & 2 & 3 & 3 & 3 & 17 \\
\hline F10 & Fruit 1 & 5 & 2 & 1 & 3 & 4 & 4 & 2 & 21 \\
\hline F11 & Fruit 2 & 5 & 1 & 1 & 3 & 4 & 4 & 4 & 22 \\
\hline F12 & Infusions & 2 & 1 & 3 & 1 & 3 & 1 & 2 & 13 \\
\hline F13 & Beans & 2 & 1 & 2 & 3 & 4 & 1 & 2 & 15 \\
\hline
\end{tabular}

In the evaluation of the $\mathrm{Y}$ axis, economic impact, Table II, four categories of quality, cost, volume and relationships were identified, from which the following evaluation criteria were selected: C1: rigor of specifications, C2: product cleaning, C3: $\%$ of total purchase value, $\mathrm{C} 4$ : price variation, $\mathrm{C} 5$ : frequency and C6: information cost; It is important to specify that the model is not static but adaptable to the characteristics of the business [22], the value of the criterion " $\mathrm{C} 3: \%$ total purchase value" has been doubled, going from 5 to 10 points, due to the abysmal difference between the first 4 elements with the rest and to make the scores more truthful. Elements P1 and P3 obtained a score of 20 and 28 points, respectively.

TABLE II

ECONOMIC IMPACT (AXIS Y)

\begin{tabular}{|c|c|c|c|c|c|c|c|c|}
\hline \multirow{2}{*}{ Internal criteria } & \multicolumn{2}{|c|}{ Calidad } & \multicolumn{2}{c|}{ Cost } & Volume & Relations & \multirow{2}{*}{ Total } \\
\cline { 3 - 8 } & & C1 & C2 & C3 & C4 & C5 & C6 & \\
\hline \multicolumn{2}{|c|}{ Item - Score } & 1 to 5 & 1 to 5 & 1 to 10 & 1 to 5 & 1 to 5 & 1 to 5 & $\mathbf{3 5}$ \\
\hline P1 & Rice & 2 & 1 & 8 & 3 & 5 & 2 & $\mathbf{2 1}$ \\
\hline P2 & Oil & 1 & 1 & 5 & 3 & 5 & 2 & $\mathbf{1 7}$ \\
\hline P3 & Chicken & 4 & 3 & 10 & 5 & 5 & 3 & $\mathbf{3 0}$ \\
\hline P4 & Bread & 2 & 3 & 6 & 1 & 5 & 1 & $\mathbf{1 8}$ \\
\hline P5 & Sugar & 1 & 1 & 6 & 2 & 5 & 2 & $\mathbf{1 7}$ \\
\hline F1 & Carne & 3 & 4 & 8 & 4 & 2 & 3 & $\mathbf{2 4}$ \\
\hline F2 & Grocery & 2 & 1 & 7 & 1 & 4 & 1 & $\mathbf{1 6}$ \\
\hline F3 & Seasoning & 2 & 3 & 7 & 3 & 3 & 3 & $\mathbf{2 1}$ \\
\hline F4 & Cereal & 2 & 3 & 4 & 3 & 3 & 2 & $\mathbf{1 7}$ \\
\hline F5 & Noodle & 3 & 3 & 3 & 2 & 5 & 2 & $\mathbf{1 8}$ \\
\hline F6 & Vegetables & 2 & 3 & 4 & 4 & 5 & 3 & $\mathbf{2 1}$ \\
\hline F7 & Tubers & 4 & 4 & 4 & 4 & 4 & 3 & $\mathbf{2 3}$ \\
\hline F8 & Limón & 3 & 1 & 5 & 2 & 5 & 1 & $\mathbf{1 7}$ \\
\hline F9 & Queso & 2 & 4 & 6 & 2 & 3 & 2 & $\mathbf{1 9}$ \\
\hline F10 & Fruit 1 & 3 & 3 & 4 & 3 & 3 & 1 & $\mathbf{1 7}$ \\
\hline F11 & Fruit 2 & 3 & 3 & 3 & 1 & 1 & 1 & $\mathbf{1 2}$ \\
\hline F12 & Infusions & 2 & 3 & 2 & 1 & 4 & 1 & $\mathbf{1 3}$ \\
\hline F13 & Beans & 3 & 3 & 8 & 4 & 4 & 2 & $\mathbf{2 4}$ \\
\hline
\end{tabular}

Once the products have been evaluated, the KPM is created and interpreted, the elements are distributed according to their 
values on both axes, obtaining 3 strategic elements, 7 levers, 6 routines and 2 bottlenecks, Fig. 4 . Element P1 is in the lever quadrant and element P3 is in the strategic quadrant.

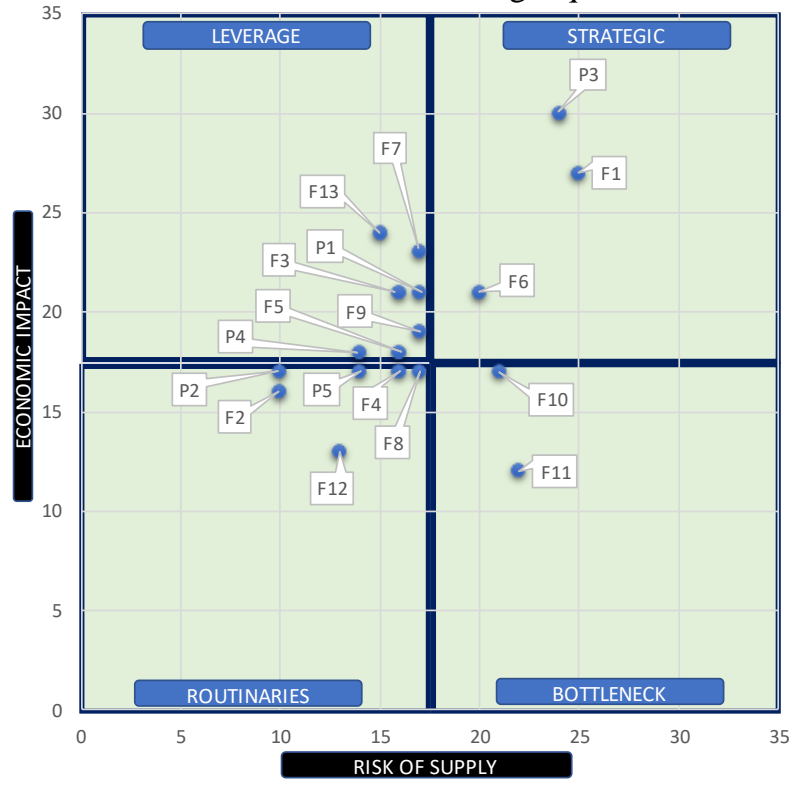

Fig. 4 Kraljic Matrix

The next step is to apply the classification implemented by Gelderman, identify opportunities to change the quadrant to the elements in order to improve the bargaining power and decrease the risk of supply, for this, areas in the Kraljic matrix will be divided, as shown in Fig. 5 and the viability of quadrant change will be considered evaluating the substitutability of the product under a Likert scale.

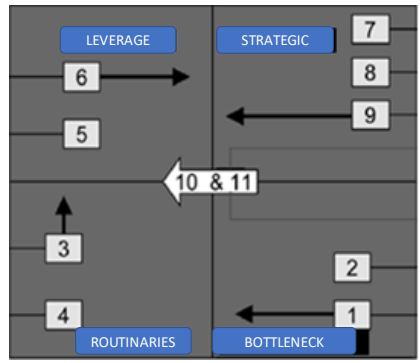

Fig. 5 Quadrant change decision matrix

After the evaluation, 6 products will change quadrant since they have an ideal location and high substitutability, Table III. Elements P1 and P3 will remain in their quadrant.

TABLE III

QUADRANT CHANGE ASSESSMENT

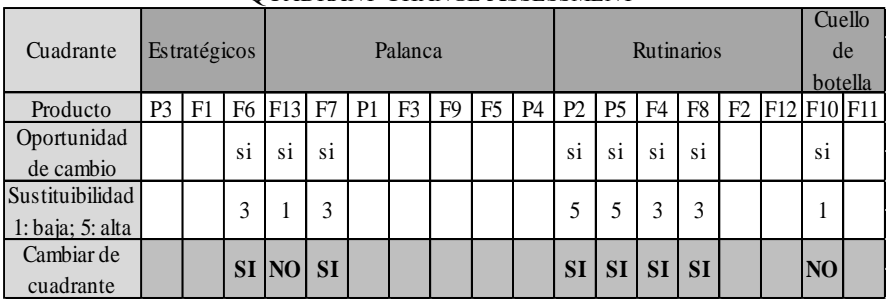

Once the strategies to be applied to each element have been defined, the suppliers are negotiated and obtain better purchase conditions, in Table IV it is classified according to the frequency and the supply characteristics, then the elements to be provisioned, discounts and the type of supply are specified. agreed delivery, the type of delivery "D" is only dispatch and "DE" is dispatch and delivery at the establishment of the company. The P1 element will be provided by a non-local supplier and with a 5\% discount of the price and the type of delivery is only dispatch, the P3 element will be provided by a local wholesaler with a $5 \%$ discount and the delivery will be at the facilities of the business.

TABLE IV

NEW PURCHASE CONDITIONS

\begin{tabular}{|c|c|c|c|c|c|c|}
\hline \multirow[b]{2}{*}{ Frequency } & \multicolumn{3}{|c|}{ Lima Supplier } & \multicolumn{3}{|c|}{ Local supplier } \\
\hline & Product & Discount & $\begin{array}{l}\text { Type of } \\
\text { delivery }\end{array}$ & Product & Discount & $\begin{array}{l}\text { Type of } \\
\text { delivery }\end{array}$ \\
\hline \multirow{2}{*}{ Daily } & & & & P3 & $5 \%$ & $\mathrm{DE}$ \\
\hline & & & & $\mathrm{P} 4$ & $5 \%$ & $\mathrm{DE}$ \\
\hline \multirow{2}{*}{$\begin{array}{c}\text { Every } 3 \\
\text { days }\end{array}$} & & & & $\mathrm{F} 1$ & $5 \%$ & $\mathrm{DE}$ \\
\hline & & & & F9 & & $\mathrm{DE}$ \\
\hline \multirow{3}{*}{ Weekly } & F6 & & D & F7 & & DE \\
\hline & $\mathrm{F} 10$ & $5 \%$ & $\mathrm{D}$ & $\mathrm{F} 8$ & $5 \%$ & $\mathrm{D}$ \\
\hline & F11 & & $\mathrm{D}$ & & & \\
\hline \multirow{9}{*}{ Monthly } & $\mathrm{F} 2$ & & $\mathrm{D}$ & & & \\
\hline & $\mathrm{F} 4$ & $5 \%$ & $\mathrm{D}$ & & & \\
\hline & P5 & $5 \%$ & $\mathrm{D}$ & & & \\
\hline & $\mathrm{P} 2$ & $5 \%$ & $\mathrm{D}$ & & & \\
\hline & F12 & & D & & & \\
\hline & F5 & & D & & & \\
\hline & P1 & $5 \%$ & $\mathrm{D}$ & & & \\
\hline & F13 & $5 \%$ & $\mathrm{D}$ & & & \\
\hline & F3 & & D & & & \\
\hline
\end{tabular}

The viability was evaluated by developing a new KPM with the new supply conditions in order to show a decrease in the risk of supply, Fig. 6; P1 and P3 decreased their risk of supply.

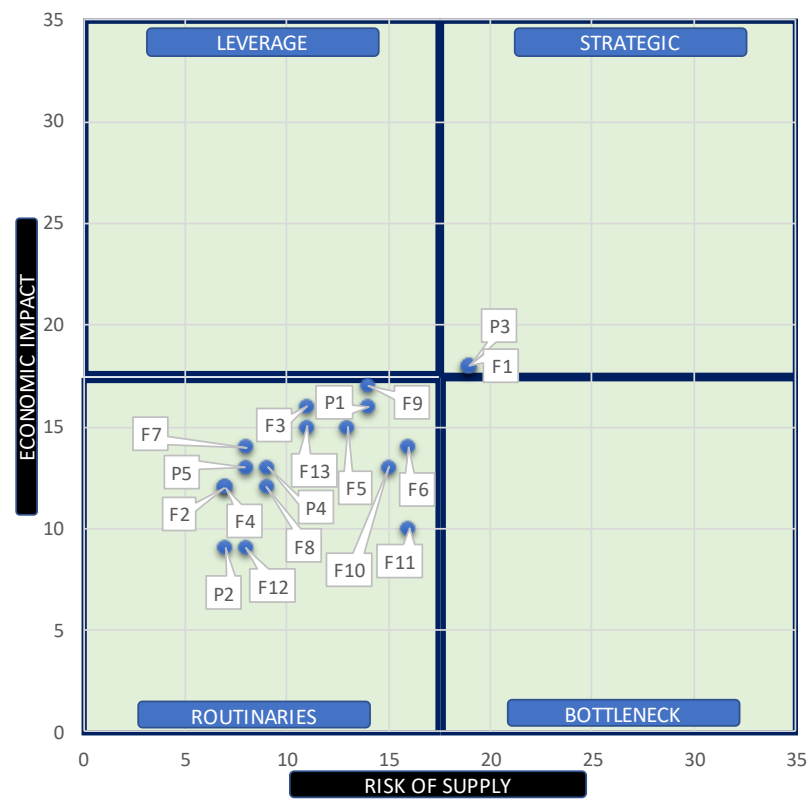

Fig. 6 New Kraljic matrix 


\subsection{Solution B: Stowage and SENASA rules}

\section{Solution B: Stowage and SENASA rules}

\begin{tabular}{|l|c|c|c|}
\hline $\begin{array}{c}\text { Current } \\
\text { method } \\
\text { analysis }\end{array}$ & $\begin{array}{c}\text { Equipment } \\
\text { identification } \\
\text { required }\end{array}$ & $\begin{array}{c}\text { Distribution } \\
\text { methodology } \\
\text { at FTU }\end{array}$ & $\begin{array}{c}\text { Development } \\
\text { of transport } \\
\text { guide }\end{array}$ \\
\hline
\end{tabular}

Fig. 7 Solution B application procedure

Solution B consists of the joint application of the SENASA transport regulations and stowage techniques, for which the scheme shown in Fig. 7 will be followed. The analysis of the current stowage method is shown in Fig. 8.

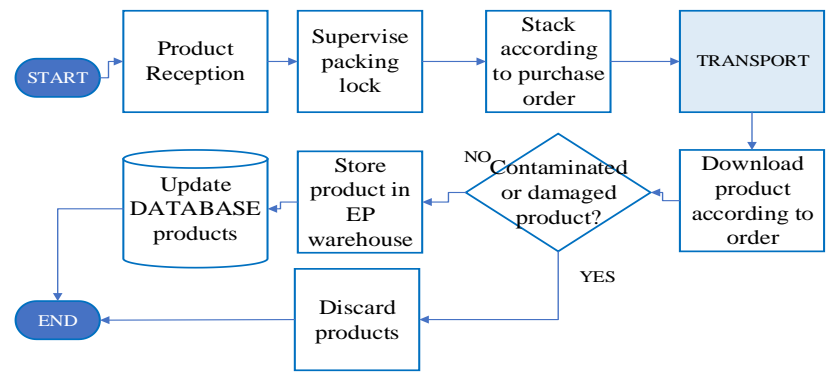

Fig. 8. Current stowage method

Fig. 8 identifies the stowage activities carried out in the stacking of products in the FTU, of which only the mooring supervision and stacking order are standardized. To contextualize this information, the structure designed by SENASA for the transport of food will be used, in which three groups are identified: preparation, loading and assurance; For the transport of the monthly volume of the company, 316 baskets with a capacity of $30 \mathrm{~kg}$ and 14 pallets of $1600 \mathrm{~kg}$ capacity, 12 straps, 200 raffia bags and the 6 metal load securing bars are required. The distribution of the FTU is carried out as stipulated by SENASA which indicates that:

- Classification of products according to nature and packaging.

- Set temporary storage area.

- Fragile products (fruits and vegetables) must be contained in baskets and must have an exclusive area.

- Grouping of products according to nature.

Once the necessary equipment and distribution criteria were defined in the FTU, the food transport guide was developed specifying the activities to be carried out, Table V:

TABLE V

FOOD TRANSPORTATION GUIDE IN FTU

\begin{tabular}{|c|l|}
\hline Stage & \multicolumn{1}{|c|}{ Proposal } \\
\hline Preparation & FTU cleaning \\
\cline { 2 - 2 } & Delimit loading areas \\
\cline { 2 - 2 } & Locate pallets. \\
\hline \multirow{3}{*}{ Load } & Appoint distribution staff \\
\cline { 2 - 2 } & Fruits and vegetables placed in the form of a uniform tower. \\
\cline { 2 - 2 } & Packaging of tubers and grains in raffia bags. \\
\hline Assurance & Check maximum pallet load capacity. \\
\cline { 2 - 2 } & Place the LDPE cover between vegetables, fruits, and grains. \\
\cline { 2 - 2 } & Place inner fixing bars for basket: 2 bars \\
\cline { 2 - 2 } & Holding sacks on each pallet using fastening straps \\
\hline
\end{tabular}

\section{Proposal implementation phases}

Developed solutions A and B, the implementation flowchart is prepared, Fig. 9. The implementation begins in August with the purchase of equipment, hiring a trainer for solution B and the contract with suppliers; in September, the specifications of consumption in terms of caliber, frequency and volume are delivered to the suppliers and a pilot transport test is carried out; and in October the purchase and transport of these is made.

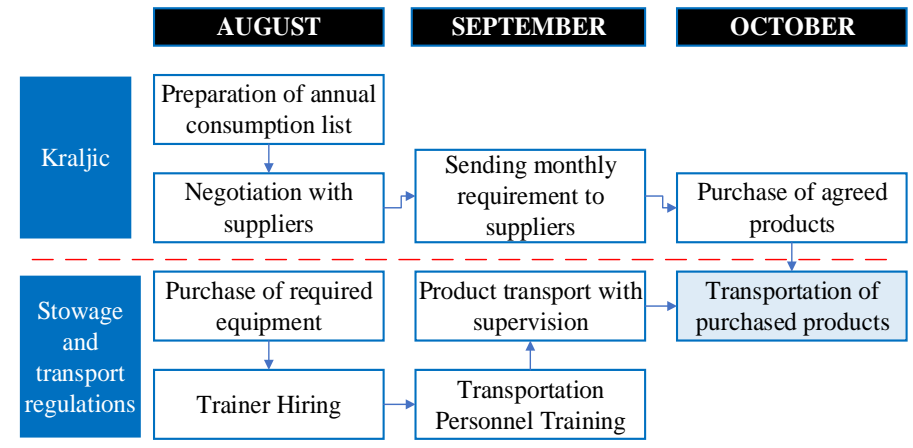

Fig. 9 Implementation flowchart

\section{Indicators of performances}

To measure the cost overrun of purchases, specific indicators were used for the root causes and one for each area studied, as shown in Table VI.

\begin{tabular}{|c|c|}
\multicolumn{2}{c}{ TABLE VI } \\
\multicolumn{1}{c}{ INDICATORS } \\
\hline Indicators & Formula \\
\hline $\begin{array}{c}\% \text { Overcost } \\
\text { per ration }\end{array}$ & $\frac{\text { total purchase value }}{\text { projected purchase value }} \times 100$ \\
\hline $\begin{array}{c}\% \text { unscheduled } \\
\text { purchases }\end{array}$ & $\frac{\text { \# unscheduled purchases }}{\text { \# total purchases }} \times 100$ \\
\hline $\begin{array}{c}\% \text { lost } \\
\text { products }\end{array}$ & $\frac{\text { Kg of lost products }}{\text { kg of products purchased }} \times 100$ \\
\hline $\begin{array}{c}\% \text { supplier } \\
\text { reliability }\end{array}$ & $\frac{\text { \# orders fulfilled }}{\text { \# total orders }} \times 100$ \\
\hline
\end{tabular}

\section{VALIDATION}

The causal situations of product losses and damages have been identified and measured as shown in Fig. 10.

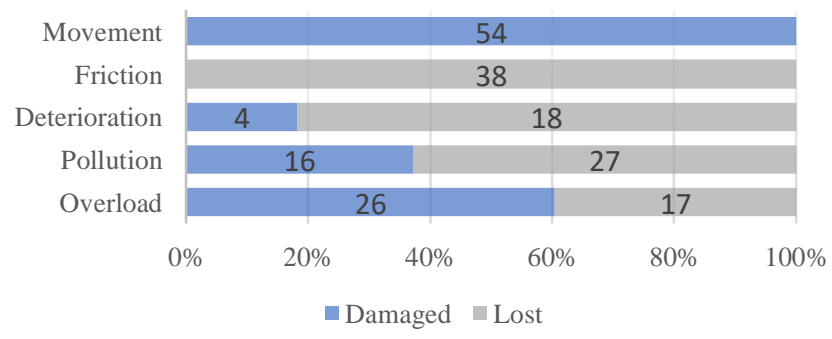

Fig. 10 Causal situations of product loss and damage. 
The values shown in Fig. 10 are units of occurrence within one year: the products have been contaminated 43 times of which 16 caused partial damage and 27 total loss of the product, also on 54 occasions there was packaging movement causing spills. which generated partial damage to the products. Defined the causal situations of product losses and the causes of unscheduled purchases, the proposals were implemented in a pilot test in the company for three months according to the data indicated in Table VII.

TABLE VII

PILOT TEST IMPLEMENTATION DETAILS

\begin{tabular}{|c|c|c|c|c|c|}
\hline \multirow{2}{*}{ Stage } & \multirow{2}{*}{ Period } & \multicolumn{4}{|c|}{ Responsible } \\
\cline { 3 - 6 } & & \multicolumn{2}{|c|}{ Solution A } & \multicolumn{2}{c|}{ Solution B } \\
\cline { 3 - 6 } & \multirow{2}{*}{$\begin{array}{c}\text { Huaraz } \\
\text { Previous } \\
\text { activities }\end{array}$} & Cugust & \multicolumn{3}{|c|}{ Ep responsible and author of the study } \\
\hline Pilot test & $\begin{array}{c}\text { September to } \\
\text { November }\end{array}$ & \multicolumn{2}{|c|}{$\begin{array}{c}\text { EP Manager and } \\
\text { Nutritionist }\end{array}$} & $\begin{array}{c}\text { Representative of the } \\
\text { Senasa }\end{array}$ \\
\hline Supervision & December & \multicolumn{4}{|c|}{ Responsible for the EP } \\
\hline \multicolumn{2}{|c|}{ \# Samples } & 4 & 2 & 8 & Chimbote \\
\hline
\end{tabular}

Pilot tests were carried out in the EPs of Huaraz and Chimbote, where 4 and 2 purchases were made respectively, and 8 and 6 transports of purchased products. The cost of implementing the pilot tests amounted to S/ 11420 in total as shown in Table VIII.

TABLE VIII

IMPLEMENTATION COST

\begin{tabular}{|c|c|c|c|c|}
\hline Concept & Capacity & Price & Amount & Total \\
\hline Transport & 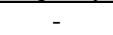 & S/ 500 & 1 & S/ 500 \\
\hline Documentation & - & S/ 200 & 1 & S/ 200 \\
\hline Basket & 25 & $\mathrm{~S} /$ & 300 & S/ 4500 \\
\hline Pallet & 1400 & $\mathrm{~S} /$ & 14 & S/ 840 \\
\hline Nylon strap & 2500 & S/ 200 & 12 & $\mathrm{~S} / 2400$ \\
\hline Bags & 80 & $\mathrm{~S} /$ & 300 & S/ 150 \\
\hline Metal bars & 1000 & $\mathrm{~S} / \quad 30$ & 6 & S/ 180 \\
\hline $\begin{array}{l}\text { Supplier } \\
\text { selection }\end{array}$ & - & S/ 1000 & 1 & S/ 1000 \\
\hline Other & - & S/ 50 & 1 & 50 \\
\hline Training & - & S/ 200 & 8 & S/ 1600 \\
\hline \multicolumn{4}{|c|}{ Total } & S/ 11420 \\
\hline
\end{tabular}

After conducting the pilot test in the stipulated period, the results were evaluated according to the indicators set out in the contribution chapter, which show a notable improvement in the decrease of the total cost overrun by $15 \%$, the $\%$ of unscheduled purchases decreased by $22 \%$ it is important to specify that this value will never be 0 since the client population is variable, the damages and losses of products are existing and average around $5 \%$ monthly and $8 \%$ has been obtained which shows a great improvement in the area In transport, the supplier's reliability indicator achieved $97 \%$ largely due to inconvenience of gauge availability and homogeneous characteristics of the required products. Fig. 11 shows the initial value of the indicators and the final value obtained post implementation

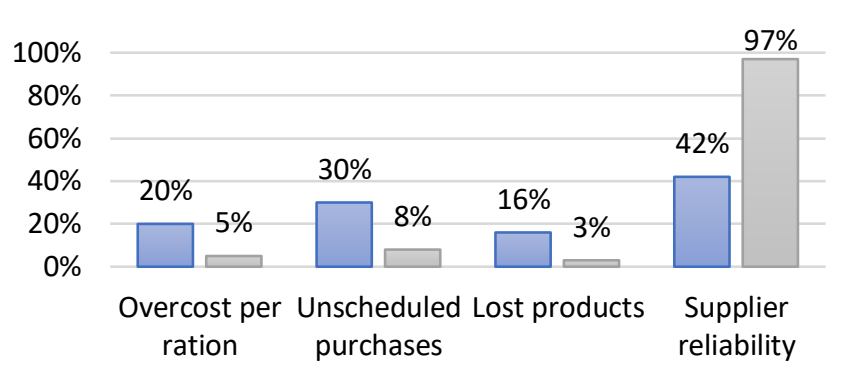

$\square$ INITIAL $\square$ FINAL

Fig. 11 Indicators: initial vs final

In monetary terms, the decrease in the cost overrun per ration means S/ 930199 annual savings, if you evaluate the economic impact of the proposal in general considering the benefits obtained by the discounts after the implementation in an annual projection are S/ 157 464, Table IX.

In short, the company under study in one year has gone from having a loss of S/ 1007035 to generating an extra income of S/ 157464 derived from a purchase planning specific to its consumption volume.

TABLE IX

ANNUAL SAVINGS IN SOLES (S/)

\begin{tabular}{|c|c|c|c|c|}
\hline Concept & \multicolumn{2}{|c|}{ Monthly } & \multicolumn{2}{|r|}{ Annual } \\
\hline Initial overcost & $-\mathrm{S} /$ & 83920 & $-\mathrm{S} /$ & 1007035 \\
\hline Current overcost & $-\mathrm{S} /$ & 6403 & $-\mathrm{S} /$ & 76836 \\
\hline \multicolumn{3}{|c|}{ Decrease in overcost } & $-\mathrm{S} /$ & 930199 \\
\hline Concept & \multicolumn{2}{|c|}{ Monthly } & & Annual \\
\hline Current overcost & $-\mathrm{S} /$ & 6403 & $-\mathrm{S} /$ & 76836 \\
\hline Discounts & $+\mathrm{S} /$ & 19525 & $+\mathrm{S} /$ & 234300 \\
\hline \multicolumn{3}{|c|}{ Decrease in overcost } & $+\mathrm{S} /$ & 157464 \\
\hline
\end{tabular}

\section{DISCUSSION}

An evaluation of the results obtained during the implementation was carried out, for them 4 specific situations have been identified which are differentiated from the rest, the 4 situations correspond to the first and second purchase and joint transport for both EP, the first purchase and transport only of the EP of Chimbote and the last one corresponds to the first transport of only fruits and vegetables for both EP, the results obtained are shown in Table $\mathrm{X}$, in this table it is evidenced that during the first purchase the highest value of unsatisfied purchases was obtained due Since the suppliers still did not have the volume with the required characteristics available in the required time, in the transport of only fruits and vegetables the highest cost per ration was obtained, due to the volatility of their prices which had an increase on the day of the purchase mitigated a little that low values were obtained in the rest of the indicators, the reliability indicator remained stable from the third scenario achieving an average of $97 \%$. 
TABLE $X$

IMPLEMENTATION STAGE INDICATORS

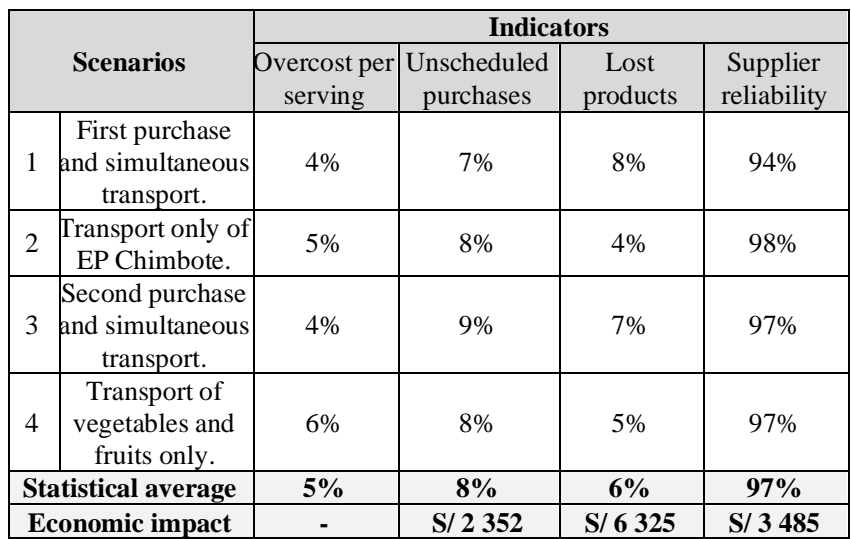

Two analysis criteria were applied, the first one is the statistical average which shows that the cost overruns are being kept below $10 \%$. In fact, this indicator has an average of 5\%, unscheduled purchases are below expected since to a large extent this is affected by the constant variation of the public client which is unpredictable to predict the time in which said event occurs. The second criterion is the financial one which measure soles monetary terms $(\mathrm{S} /)$ The impact of each of the indicators for the economy of the company in a month, for example, the decrease in the $\%$ of unscheduled purchases meant for the company S/ 2352 and saved S/ 6325 dues to the decrease in lost products.

\section{CONCLUSIONS}

The application of the KPM to define purchasing strategies allows to reduce the cost overruns of unplanned purchases incurred due to planning errors and reprocessing of purchases. This strategy is reinforced if stowage and food transport techniques are added, as it covers both the planning and the staging of the designed strategies.

The KPM allows to improve the bargaining power by volume and grouping of products to obtain a considerable discount if the material is provided to establish a stable and longterm relationship with the suppliers, for this a great effort and coordination between the company and the provider.

Working with a standardized transport methodology allows product losses to be reduced, since the entire process is controlled and monitored, from loading, stowage, insurance and transport.

\section{REFERENCES}

[1] P. Ariya and N. Chakpitak, "Systems thinking in online travel agency of supplier relationship management," Int. J. Innov. Learn., vol. 19, no. 1, pp. 63-84, 2016.

[2] S.-Y. Lee, "Responsible supply chain management in the Asian context: the effects on relationship commitment and supplier performance," Asia Pacific Bus. Rev., vol. 22, no. 2, pp. 325-342, 2016.

[3] S. R. Gangurde and A. A. Chavan, "Benchmarking of purchasing practices using Kraljic approach," Benchmarking, vol. 23, no. 7, pp. 1751-1779, 2016.
[4] I. Vlachos, "Applying lean thinking in the food supply chains: a case study," Prod. Plan. Control, vol. 26, no. 16, pp. 1351-1367, Dec. 2015.

[5] L. Jerman and S. Nogatchewsky, "Purchasing segmentation in customersupplier relationships | Segmentation achats dans la gestion des relations client-fournisseur," Rev. Fr. Gest., vol. 248, no. 3, pp. 135-152, 2015.

[6] N. Vlachakis, A. Mihiotis, C. P. Pappis, and I. N. Lagoudis, "A methodology for analyzing shipyard supply chains and supplier selection," Benchmarking, vol. 23, no. 2, pp. 443-455, 2016.

[7] R. T. Montgomery, J. A. Ogden, and B. C. Boehmke, "A quantified Kraljic Portfolio Matrix: Using decision analysis for strategic purchasing," J. Purch. Supply Manag., vol. 24, no. 3, pp. 192-203, 2018.

[8] M. Silva and P. S. Figueiredo, "Supplier selection: A proposed framework for decision making," Int. J. Procure. Manag., vol. 11, no. 2, pp. $233-$ 249, 2018.

[9] M. Shlopak, E. Rød, and O. Oterhals, Developing supplier strategies for eto companies: A case study, vol. 488. 2016.

[10] T. Verduzco-Garza, M. Cisneros, F. Lopez, and D. Santiago, "Design of a global sourcing strategy to reduce assembly components cost: A case study," in Proceedings of the International Conference on Industrial Engineering and Operations Management, 2018, vol. 2018, no. JUL, pp. 2862-2871.

[11] A. Arantes, L. M. D. F. Ferreira, and A. A. Kharlamov, "Application of a purchasing portfolio model in a construction company in two distinct markets," J. Manag. Eng., vol. 30, no. 5, 2014.

[12] S. Nazari-Shirkouhi, A. Keramati, and K. Rezaie, "Investigating the effects of customer relationship management and supplier relationship management on new product development," Teh. Vjesn., vol. 22, no. 1, pp. 191-200, 2015.

[13] M. Kang, P. Hong, R. Bartnik, Y. Park, and C. Ko, "Aligning purchasing portfolio management with sourcing negotiation styles," Manag. Decis., vol. 56, no. 11, pp. 2341-2356, 2018.

[14] R. Directoral and E. Informe---minagri-senasa-diaia-, "Aprueban formatos de evaluación sanitaria para la certificación de puestos de venta saludables de alimentos agropecuarios primarios y piensos, en mercados de abasto," 2018.

[15] MINAGRI (Ministerio de Agricultura y Riego), "Guía Práctica: Dirigida a Productores Emprendedores Reglamento de Inocuidad Alimentaria," p. 51 p., 2013.

[16] C. Cheng, Y. Wu, and Q. He, "Study on truck stowage planning of cargo distribution center in a town," in Proceedings - International Conference on Intelligent Computation Technology and Automation, ICICTA 2008, 2008, vol. 2, pp. 509-512.

[17] S. Zander and L. M. Kolbe, "Supplier relationship management in information systems research: A literature review," 2016, vol. 1, pp. 479490.

[18] SENASA, "Manual de Capacitación para Transportistas," 2019.

[19] SENASA, "Guía de inocuidad," 2018.

[20] C. J. Gelderman and D. R. Mac Donald, "Application of Kraljic's purchasing portfolio matrix in an undeveloped logistics infrastructure: The staatsolie suriname case," J. Transnatl. Manag., vol. 13, no. 1, pp. $77-92,2008$.

[21] F. H. Hesping and H. Schiele, "Matching tactical sourcing levers with the Kraljič matrix: Empirical evidence on purchasing portfolios," Int. J. Prod. Econ., vol. 177, pp. 101-117, 2016.

[22] W. van der Valk and B. Axelsson, "Towards a managerially useful approach to classifying services," J. Purch. Supply Manag., vol. 21, no. 2, pp. 113-124, 2015. 